\title{
The kallikrein-Kinin system modulates the progression of colorectal liver metastases in a mouse model
}

\author{
Patricia Luiza Nunes da Costa ${ }^{1,2}$, David Wynne1, Theodora Fifis ${ }^{1 *}$, Linh Nguyen ${ }^{1}$, Marcos Perini ${ }^{1}$ \\ and Christopher Christophi ${ }^{1}$
}

\begin{abstract}
Background: The Kallikrein-Kinin System (KKS) has been found to play a role in tumor progression in several cancers. The KKS metabolic cascade depends on signalling through two cross talking receptors; bradykinin receptor 1 (B1R) and bradykinin receptor 2 (B2R). Activation of the Kinin receptor is responsible for multiple pathophysiologic functions including increase of vascular permeability and induction of host inflammatory responses that exert diverse effects on tumor growth.

Methods: B1R and B2R expression on mouse and human CRC cell lines was investigated. Changes in tumor growth and progression was assessed in male CBA mice bearing colorectal liver metastases (CRLM) following treatment with B1R or B2R blockers. In vitro cultures of human SW-480 and mouse colorectal cancer (MoCR) cell lines were examined for changes in their proliferation and migration properties following treatment with B1R or B2R blockers.

Results: Both colorectal cancer cell lines tested strongly positive for B1R and B2R expression. Inhibition of both receptors retarded tumor growth but only B1R blockade significantly reduced tumor load and increased tumor apoptosis. Blockade of either receptor reduced tumor vascularization in vivo and significantly inhibited proliferation and migration of colorectal cancer cells in vitro.

Conclusion: Taken together, the present study demonstrated that kinin receptor blockade inhibited tumor growth and reduced its invading properties suggesting that KKS manipulation could be a novel target in colorectal cancer therapy.
\end{abstract}

Keywords: Colorectal liver metastases, Kallikrein-Kinin system, Bradykinin receptor, Kinin or bradykinin

\section{Background}

Colorectal cancer (CRC) is the third most common cancer worldwide [1]. The majority of CRC related deaths are associated with liver metastasis [2, 3]. Surgical removal of colorectal liver metastases (CRLM) supported by systemic chemotherapy provides the best possibility for cure in a percentage of patients and even among these, $30 \%-60 \%$ will develop tumor recurrence in the liver or in other organs $[4,5]$. Recent studies have demonstrated involvement of the renin angiotensin system (RAS) in cancer progression, including CRLM [6, 7].

\footnotetext{
*Correspondence: tfifis@unimelb.edu.au

'Department of Surgery, University of Melbourne, Austin Health, Lance Townsend Building Level 8, Studley Rd, Heidelberg, VIC 3084, Australia Full list of author information is available at the end of the article
}

There is also evidence of crosstalk between the Kallikrein Kinin System KKS and RAS pathways. The angiotensin-converting enzyme (ACE) catalyses both the production of angiotensin II and the degradation of bradykinin, suggesting a cross-regulation between the two systems [8], however the effects of the Kallikrein Kinin System (KKS) on CRLM have not been as well studied.

The role of kinin receptors in cancer has been investigated [9-11]. Many cancer tissues display higher expression of B1R and/or B2R compared to their normal counterparts [9]; 'kinin' in humans and most mammal contexts refers to bradykinin (BK). Signalling by BK through either B1R, B2R or both can promote angiogenesis in different experimental models by promoting vascular cell proliferation and 
survival, and by increasing vascular permeability [12, 13]. Selective antagonists of B1R or B2R have shown antiproliferative, anti-inflammatory, anti-angiogenic and antimigratory properties $[9,12,14]$. Kinin receptors have been reported in mouse and human colon carcinoma cell lines $[15,16]$. BK treatment of the CRC cell line SW-480 results in mitogenic activation [16]. Zelawski et al. found a higher $\mathrm{B} 1 \mathrm{R}$ expression in human tubular adenomas, a benign tumor that can become colonic carcinoma, suggesting that kinins may contribute to cellular transformation [17].

While the literature support the role of the Kallikrein Kinin System (KKS) signalling in tumor aggressiveness and progression, additional studies are needed in relevant animal models that closely represent the clinical tumor progression. We have developed and characterised a mouse model of CRLM in a fully immunocompetent host which we used in the present study to investigate the effects of kinin receptor inhibition on the CRLM tumors. Additionally we investigated the direct effects of KKS inhibitors on cultured CRC cell proliferation and migration.

\section{Methods}

Animals

CBA strain mice (Laboratory Animal services, University of Adelaide, South Australia) were used. Mice were kept in standard cages (2-5 animals per cage) in rooms with $12 \mathrm{~h}$ light/dark cycle, constant temperature and humidity. Food and water were provided ad libitum. Environmental enrichment was provided in the form of dry tissue ribbons and cardboard tunnels. All animal experiments were approved by the Austin Health Animal Ethics Committee.

\section{Mouse model}

Liver metastases were established by intrasplenic injection. as described previously $[6,18]$ Briefly, $2.5 \times 10^{4}$ MoCR cells were injected into the spleen of 6 to 8 week old male CBA mice (body weight 24-28 g), under anaesthesia (isoflurane) following an abdominal incision to exteriorize the spleen. Mice were given long-acting analgesic (carprofen, $5 \mathrm{mg} / \mathrm{kg}$ ) just before surgery, hydrating jelly post surgery and were monitored closely for the next $24 \mathrm{~h}$. In this model tumors are well established by day 21 post-induction, when liver samples were collected and fixed in fresh $10 \%$ formalin.

\section{Drugs/agents and treatments for the in vivo studies}

Three groups of six animals were used, one control and two experimental groups. Animals were assigned randomly to each group. The B1R inhibitor (SSR240612) was given at $15 \mathrm{mg} / \mathrm{kg} /$ day. The B2R inhibitor (FR173657) was given at $15 \mathrm{mg} / \mathrm{kg}$ twice daily (early morning and late afternoon), totalling $30 \mathrm{mg} / \mathrm{kg} /$ day. Both drugs were dissolved prior to administration in 10\% DMSO diluted in distilled $\mathrm{H}_{2} \mathrm{O}$. Control animals were administered $10 \%$ DMSO in distilled $\mathrm{H}_{2} \mathrm{O}$. Each treatment was administered via oral gavage (volume of $0.25 \mathrm{ml}$ ) starting from day 1 post tumor induction.

\section{Stereological assessment of tumor growth}

Tumor volume and burden were assessed using quantitative stereology as described previously [19]. Briefly the fixed tissues were sliced into $1.5 \mathrm{~mm}$ sections and imaged using a Lumenera Infinity4 digital CCD camera. The imaging software Image-ProPlus 6.0 was used to collect the data. The researcher collecting the data was blinded in regards to the group origin of the tissue.

\section{Immunohistochemistry}

Immunohistochemistry and data collection were performed as described previously [20] Changes in tumor angiogenesis and apoptosis were determined by immunostaining formalin fixed liver tissues with anti-CD34 (rat anti-mouse monoclonal, Serotec MCA 18256 at $1 \mu \mathrm{g} / \mathrm{ml}$ and anti-Caspase 3 (rabbit polyclonal, R\&D system AF835 at $2 \mu \mathrm{g} / \mathrm{ml}$ ) antibodies, respectively. Antigen retrieval was performed by heat in citrate buffer.

\section{Human and mouse cell lines}

SW480 (ATCC ${ }^{\oplus}$ CCL-228 $^{\text {TM }}$ ) cell line is a human colorectal cancer cell line, derived from grade 3-4 colon adenocarcinoma and grown adherent in cell culture. SW480 cells were cultured in DMEM/10\% FBS at $37{ }^{\circ} \mathrm{C}$ and $5 \% \mathrm{CO}_{2} / 95 \%$ air. The mouse MoCR cell line used in the current studies was originally derived in our laboratory from a dimethyl hydrazine-induced CBA mouse colon carcinoma as described previously [18] MoCR cells were cultured in $\mathrm{RPMI} / 10 \% \mathrm{FBS}$ at $37^{\circ} \mathrm{Cand} 5 \% \mathrm{CO}_{2} / 95 \%$ air. Both cell lines were mycoplasma free upon testing. Culture passages 4-15 were used for the experiments described in these studies.

\section{Drugs/agents and treatments for the in vitro studies}

SSR240612 (Sanofi Aventis) was used at $10 \mu \mathrm{M}$ to block B1R and FR173657 (Astellas Pharma) at $10 \mu \mathrm{M}$ to block B2R. The agonist desArg9-Bradykinin (DABK) (SigmaAldrich) at $0.1 \mu \mathrm{M}$ was used to activate B1R. Bradykinin fragment $1-8$ (BK) (Sigma-Aldrich) at $0.1 \mu \mathrm{M}$ was used to activate B2R.

\section{Proliferation assay}

Cell proliferation was determined by counting the incorporation of [H3]-thymidine. Cells were seeded at $6 \times 10^{4}$ cells/well in RPMI/10\%FBS (MoCR cells) or DMEM/ $10 \%$ FBS (SW480) in 96-well plates and allowed to adhere overnight before being starved in 0\% FBS RPMI or DMEM for 18 h. Following starving, fresh RPMI/DMEM 
and $10 \mu \mathrm{Ci} / \mathrm{ml} 3 \mathrm{H}$-thymidine, $+/$ - agonists (DABK or BK) and/or antagonists (SSR240612 or FR173657) were added and cultured for $48 \mathrm{~h}$. The cell cultures were then collected using the NUNC cell harvester. The $3 \mathrm{H}$-thymidine incorporation into the dividing cells was measured using a $\beta$-counter (Packard, Meriden, CT).

\section{Cell migration/invasion assay}

A modified Boyden Chamber assay [21] was used to investigate cell migration and invasion. Briefly membranes (8- $\mu$ m pore size, BD353097, Becton Dickinson, NJ, USA) were coated with $30 \mu \mathrm{g} / 30 \mu \mathrm{l}$ fibronectin (BD3534009, Becton Dickinson, USA) on their lower surface and placed into the wells of a 24-well plate containing $600 \mu \mathrm{l} /$ well serum-free RPMI and 0.1\% BSA. Tumor cells $\left(2-5 \times 10^{4}\right.$ cells $\left./ 100 \mu \mathrm{l}\right)$ were added to the upper chamber in the presence or absence of agonists (DABK or BK) and/or antagonists (SSR240612 or FR173657). The plates were placed in a humidifying incubator for $24 \mathrm{~h}$ at $37{ }^{\circ} \mathrm{C}$ and $5 \% \mathrm{CO}_{2}$. The cells on the upper surface of the membranes were removed and the cells on the lower surface were fixed, stained with Quick-Dip (Fronine,
Sydney, Australia) and counted using a NIKON Coolscope (Coherent Scientific, Adelaide, Australia).

\section{Statistical analysis}

Data was analysed using the statistical software package SPSS (SPSS Version 17.0; IBM Co., Armonk, NY, USA). Quantitative data are presented as mean values \pm S.E.M. for each group. Parametric data was analysed using ANOVA with post hoc comparison (Tukey method) for parametric data and Mann-Whitney $U$ test for nonparametric data. A $p$ value $\leq 0.05$ was considered statistically significant.

\section{Results}

Mouse and human CRC cell lines express B1R and B2R.

We first wanted to establish whether our CRC cell lines (MoCR and SW480) express B1R and/or B2R. Immunohistochemical staining for these receptors confirmed their expression (Additional file 1), supporting previous published studies that CRC cells express bradykinin receptors [22].

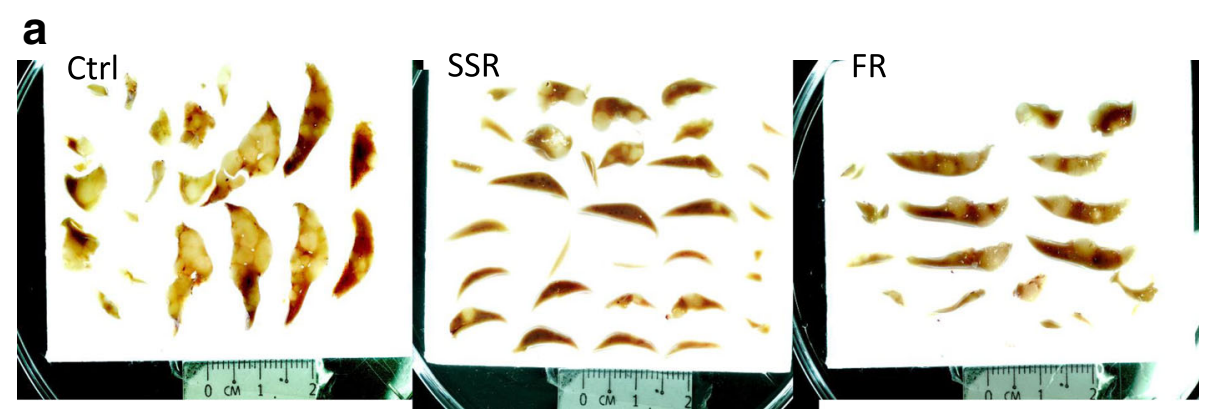

b

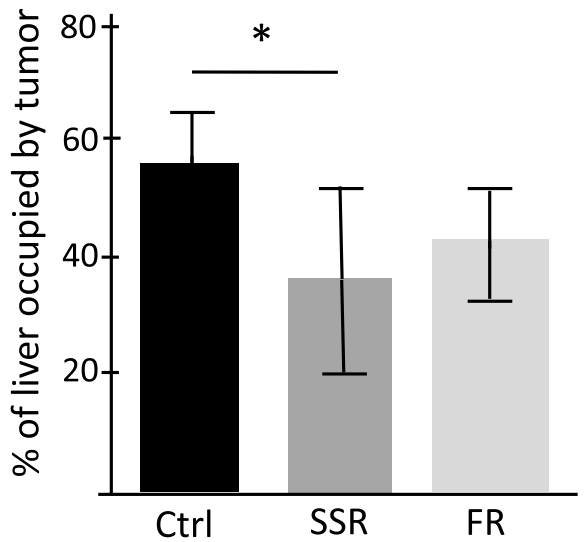

C

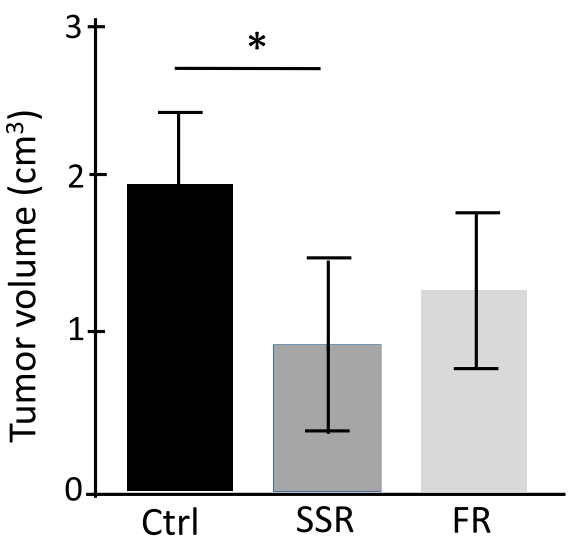

Fig. 1 The effect of kinin receptor inhibition on CRLM tumor growth in CBA mouse model. CBA mice, 6 per group, underwent tumor induction surgery and were treated with SSR240612 (SSR) (15 mg/kg/day), FR173657 (FR), (30 mg/kg/day) or vehicle solution (Ctrl) daily via oral gavage starting at day 1 post tumor induction. Livers were collected on day 21 and were fixed in formalin. a represtative images of liver sections used to determine percentage tumor occupancy and total tumor volume were determined by stereological analysis using Image ProPlus 6. b Percentage tumor occupancy of the liver and $\mathbf{c}$ total tumor volume were significantly reduced following SSR240612 treatment Results are presented as mean \pm SD, $\left({ }^{*} p<0.05\right.$ compared to control) 
B1R blockade reduced tumor burden in a mouse model. To investigate whether modulation of signalling through the $\mathrm{B} 1 \mathrm{R}$ or the $\mathrm{B} 2 \mathrm{R}$ affects tumor progression, B1R (SSR240612) or B2R (FR173657) blockers were given to six mice/group harbouring tumor metastases. Quantitative stereology analysis of tumor growth at day 21 post tumor induction demonstrated a decrease in tumor load following both treatments, however this did not reach significance for $B 2 R$ blocker $\left(\mathrm{P}^{<} 0.05\right.$ for the $\mathrm{B} 1 \mathrm{R}$ blocker and $P=0.16$ for the B2R blocker) (Fig. 1A). Similarly there was tumor volume reduction compared to control $\left(\mathrm{P}^{<} 0.05\right.$ for the $\mathrm{B} 1 \mathrm{R}$ blocker and $P=0.12$ for the $\mathrm{B} 2 \mathrm{R}$ blocker) (Fig. 1B).

Further analysis focusing on the percentage of viable tumor following SSR and FR treatments revealed a significantly lower percentage of viable tumor load in animals treated with the B1R blocker SSR (8\% less viable tumor load, ${ }^{*} P=0.016$ ) (Fig. 2). No reduction in viable tumor load was observed following FR treatment compared to control $(P=0.88)$ (Fig. 2).

\section{B1R blockade increased tumor apoptosis in vivo}

We further investigated the effect of kinin receptor blockade on tumor cell apoptosis. Immunohistochemistry staining demonstrated significant increase in tumor cells undergoing apoptosis following SSR treatment. Tumors treated with SSR had 86\% more apoptosis compared to controls $(* p<0.05)$; FR treatment did not increase apoptosis compared to controls (Fig. 3).

\section{Kinin receptor blockade inhibited angiogenesis}

Previous studies have suggested an important role of $\mathrm{KKS}$ in promoting angiogenesis, increasing vascular permeability and expression of VEGF in solid tumors. To investigate if this is also a mechanism of tumor modulation in our model we examined the tumors for changes in vessel density following treatment with B1R and B2R receptor blockers. The results demonstrate both SSR and FR treatment resulted in significant reduction in angiogenesis compared to controls $(48 \%, * *<<0.0001$; $39 \%,{ }^{*} p<0.001$, respectively) (Fig. 4).
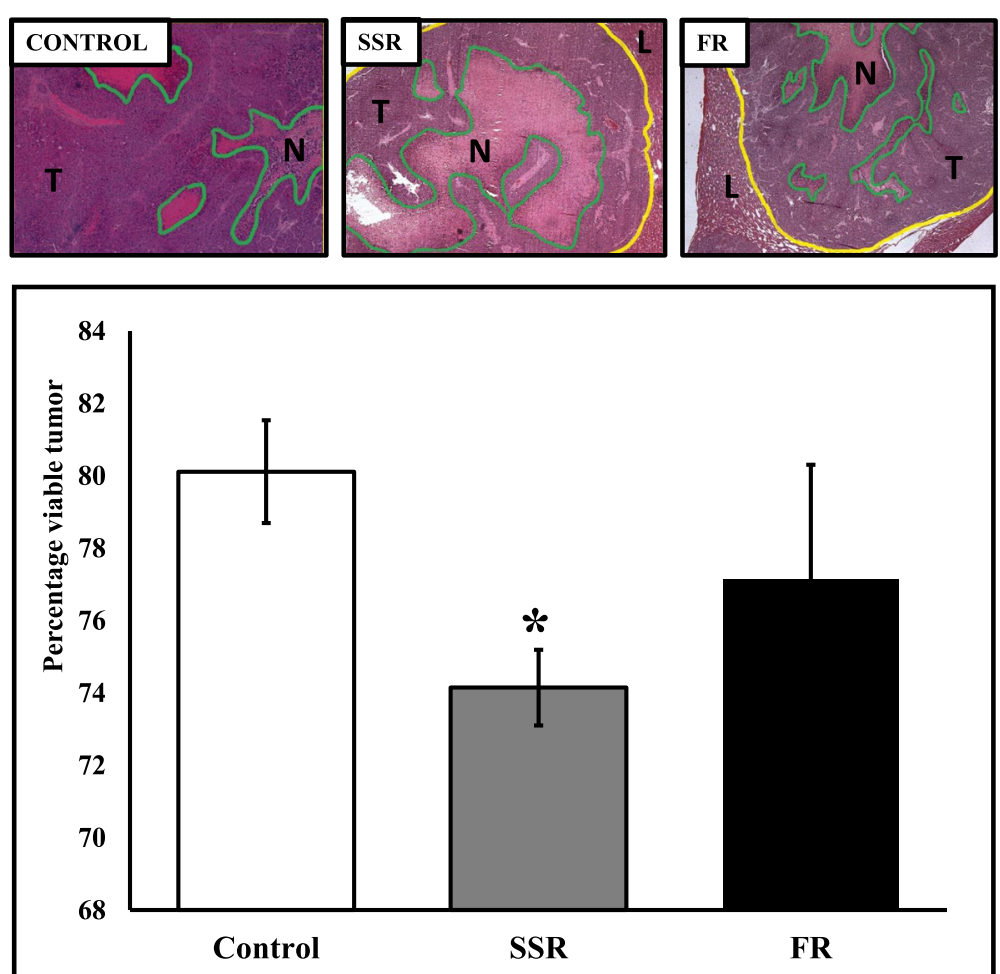

Fig. 2 Effect of kinin receptor inhibition on viable tumor growth in CBA mice induced with CRLM. CBA mice, 6 per group, underwent tumor induction surgery and were treated with SSR240612 (SSR), (15 mg/kg/day), FR173657 (FR), (30 mg/kg/day) or vehicle solution (CONTROL) daily starting at day 1 post tumor induction via oral gavage. Livers were collected on day 21 post tumor induction. Percentage of viable tumor was quantitated by Haematoxylin and Eosin staining (necrotic regions display absence of cell membranes and pycnotic nuclei if present). 10 to 20 images at $5 \times$ magnification of stained tumor from each mouse were taken in a pre-determined systematic fashion. Yellow lines show tumor area, $T=$ live tumor area, $\mathrm{N}=$ necrotic tumor enclosed within green lines. SSR treatment significantly decreased the percentage of viable tumor load in animals $\left({ }^{*} P=0.016\right)$. The reduction in viable tumor load was not observed following FR treatment compared to control $(P=0.88)$. Results are presented as group mean value \pm SD 

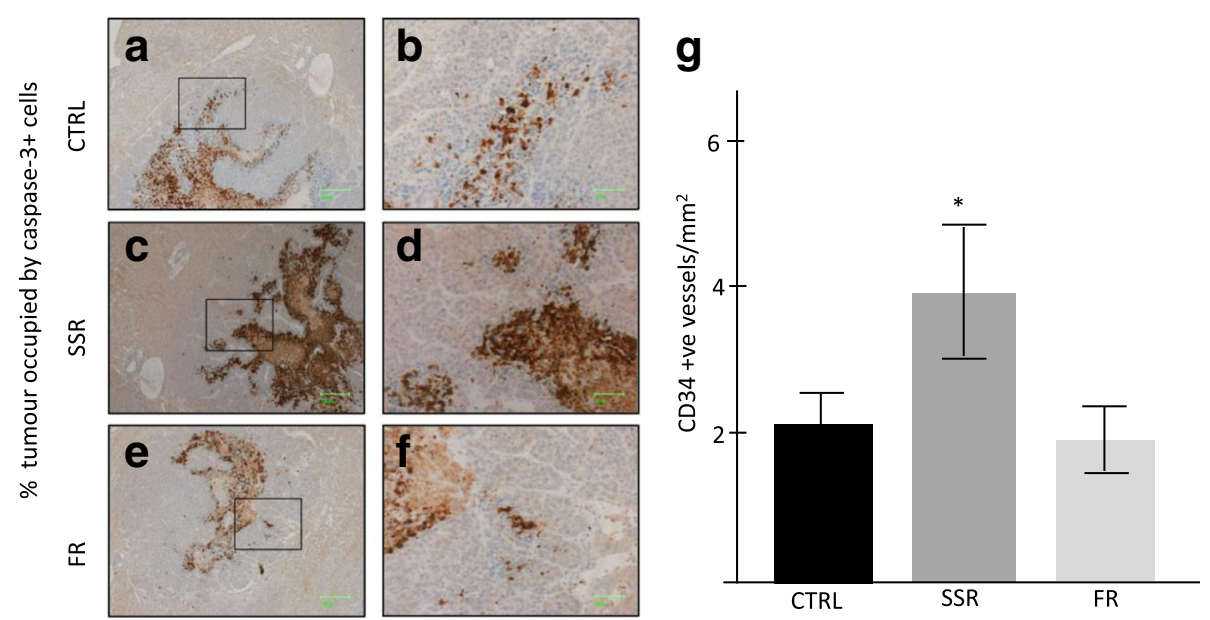

Fig. 3 Effect of kinin receptor inhibition on tumor cell apoptosis in CBA mice induced with CRLM. (CTRL=Control, SSR=SSR240612, FR=FR173657). Apoptotic tumor cells in CRLM tumors were visualised by immunostaining for caspase-3 (brown staining). a, c \&e magnification 5X, a, d \&f (corresponding insets) magnification 20x. 40 to 100 images at 20x magnification of stained tumor from each mouse were taken in a pre-determined systematic fashion. Caspase-3 positive cells were counted as a percentage of tumor area using Image ProPlus 6. SSR240612 treatment significantly increased the number of tumor cells undergoing apoptosis. Results are presented as group mean value $\pm \mathrm{SD}$, (*p $<0.05$ compared to control), $n=6$

\section{Bradykinin receptor blockers inhibited in vitro tumor cell proliferation}

Having established that blocking the B1R and B2R signalling slows CRC tumor progression and that CRC tumor cells express bradykinin receptors we wanted to know if receptor activation or blockade modulate tumor cell characteristics directly. The stimulation of the receptors on cell proliferation was also examined in MoCR cells by the addition of agonists $0.1 \mu \mathrm{M}$ DABK (B1R) or BK (B2R). Exposure to $0.1 \mu \mathrm{M}$ of DABK did not significantly change the proliferation of MoCR cells. In contrast 0 .
$1 \mu \mathrm{M}$ of BK increased MoCR proliferation by $30 \%$ at $48 \mathrm{~h}$ after treatment $\left({ }^{*} P<0.05\right)$ (Additional file 2).

We then investigated the effects of the inhibitors on MoCR and SW480 cell cultures. The cultures were treated with the receptor blockers SSR240612 (B1R) or FR173657 (B2R) at $10 \mu \mathrm{M}$ in the presence or absence of the respective agonists and their effect on cell proliferation was determined using proliferation assays as described. Significant reduction in proliferation was seen in both cell lines (Fig. 5) following SSR ( $* * * 0<0.0001$ for both cell lines) and FR treatment $\left(" p<0.001\right.$, in MoCR and ${ }^{* *} p<0.0001$ in SW480).
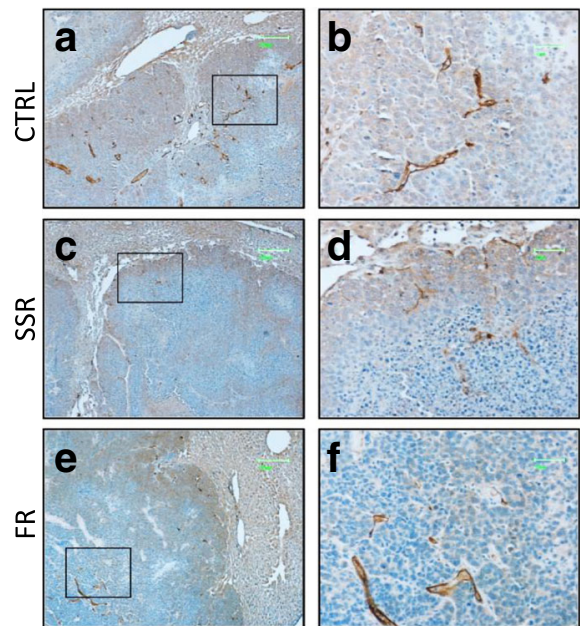

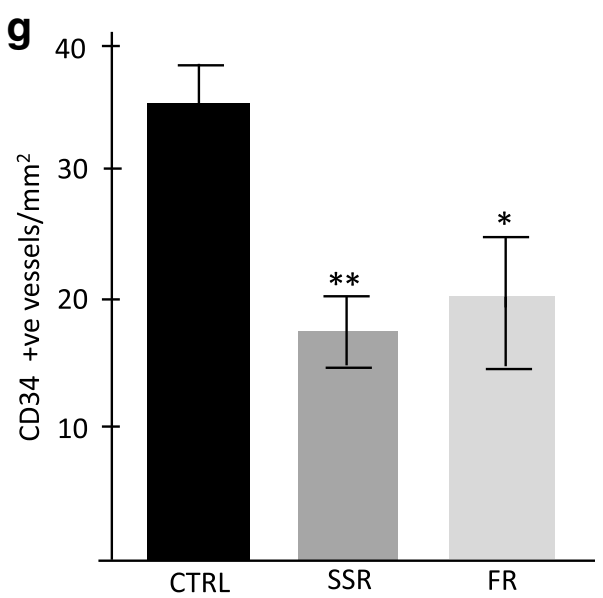

Fig. 4 Effect of kinin receptor inhibition on tumor angiogenesis in CBA mice induced with CRLM. Tumor blood vessels were visualised by immunostaining for CD34 endothelial cell marker (brown staining). a,c\&e magnification 5x, a,d\&f (corresponding insets) magnification 20x, 0 to 100 images at 20x magnification of stained tumor from each mouse were taken in a pre-determined systematic fashion. CD34 positive blood vessels were counted using Image ProPlus 6. SSR240612 (SSR) and FR173657 (FR) treatment significantly reduced tumor angiogenesis compared to control (CTRL) shown in $\mathbf{g}$. Results are presented as group mean value $\pm S D,(n=6)\left({ }^{*} p<0.001 ;{ }^{*} p<0.0001\right.$ compared to control) 


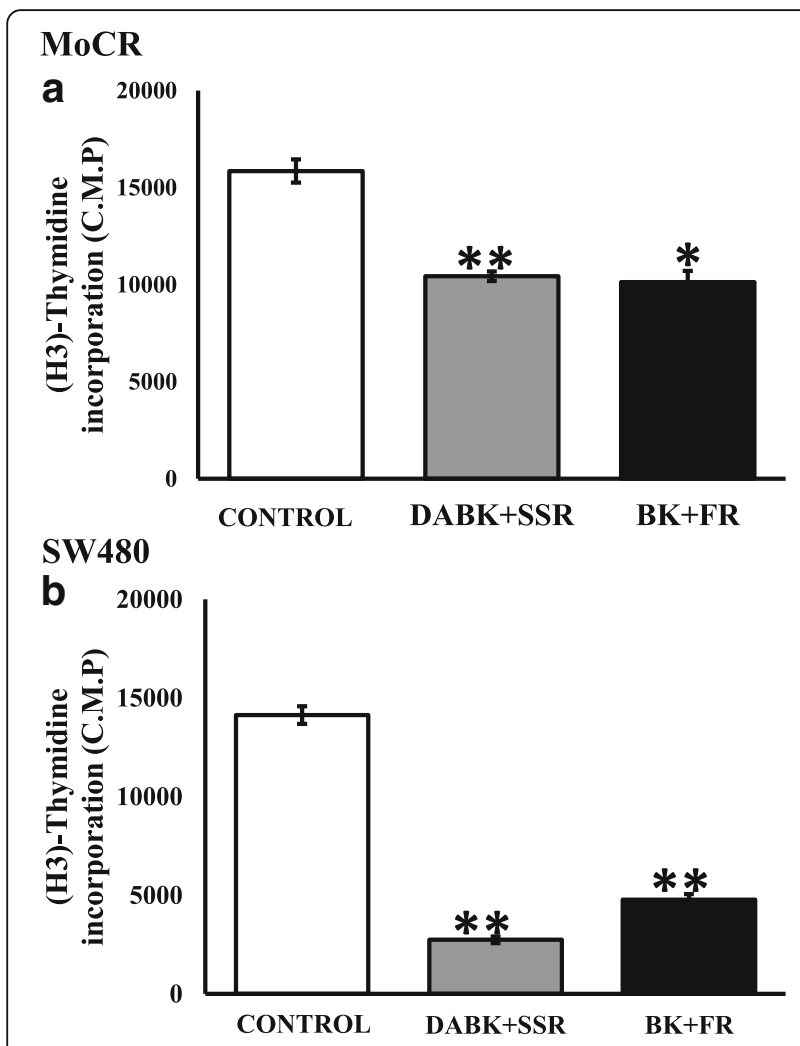

Fig. $\mathbf{5}$ The effect of kinin receptor antagonists on MoCR and SW480 cell proliferation. a MoCR cells and $\mathbf{b}$ SW480 cells were cultured for $48 \mathrm{~h}$ in RPMI media in the presence of $0.10 \mu \mathrm{M}$ of kinins (BK or DABK) and $10.0 \mu \mathrm{M}$ of the B2R antagonist FR173657 (FR) or the B1R antagonist SSR240612 (SSR) in specific combinations. The control was RPMI media with no FBS, SSR240612 and FR173657 treatment significantly reduced tumor cell proliferation compared to control cells. Results are presented as replicate mean $\pm S D, 4$ replicate per group $\left({ }^{*} \mathrm{p}<0.001 ;{ }^{* *} \mathrm{p}<0.0001\right.$ compared with untreated control)

The reduction of proliferation was the same whether the agonists were present (Fig. 5) or absent. (Not shown).

\section{B1R and B2R blockade inhibited kinin mediated invasion in CRC}

Treatment with 0.1 and $1 \mu \mathrm{M}$ BK promoted cell invasion in MoCR cells (Additional file 3). The effect of B1R and $\mathrm{B} 2 \mathrm{R}$ blockade on tumor cell invasion in the presence of agonists was also tested. Invasion assays were performed following $\mathrm{DABK}+\mathrm{SSR}$ or $\mathrm{BK}+\mathrm{FR}$ treatment and quantified 21 h later. As shown in Fig. 6, addition of kinin receptor blockers resulted in over $90 \%$ reduction of invasion in MoCR cells. Treatment with agonists in the presence of inhibitors (DABK+SSR and BK + FR) did not restore invasion $\left(\mathrm{p}^{* *}<0.0001\right)$ compared to untreated controls.

\section{Discussion}

The KKS is a complex multifunctional signalling cascade and its role in cancer remains unclear. Early reports on the likely role of the KKS in cancer suggested enhanced vascular permeability and upregulation of nitric oxide synthase and prostaglandin $[23,24]$. This led to the suggestion that KKS family members may be novel biomarkers for cancer [25-28]. More recent studies further support the role of the KKS in cancer development [7, 29] and a number of KKS generated proteins confirmed to exhibit pro-inflammatory properties [30]. Chronic inflammation is tightly associated with cancer development and progression [31].

In this study B1R or B2R blockade led to reduction in tumor progression compared to untreated controls, however this reduction did not reach significance for B2R blockade. Blockade of B1R resulted in significant viable tumor reduction and significant increase in apoptosis suggesting that the reduction in tumor progression is effected, at least in part, through tumor cell apoptosis. In contrast there was no reduction in the percentage of viable tumor or increase in apoptosis associated with B2R blockade. It has been shown that B1R and B2R can activate several intracellular signalling pathways including NF- $\mathrm{kB}[32,33]$. Indeed the $\mathrm{p} 53$ and NF- $\mathrm{kB}$ pathways are, arguably, the two major cellular stress response pathways leading to pro-apoptosis or anti-apoptosis pathways respectively. Webster et al. demonstrated that during injury or stress there is crosstalk between NF- $\mathrm{B}$ and $\mathrm{p} 53$; they showed that these two transcription factors can modulate each other's functions depending on their relative levels present. Following injury, the ability of NF-kB to supress p53 can determine the cell fate [34]. Although both B1R and B2R have been shown to induce NF-kB activation; the patterns of signalling are different in terms of duration and intensity [35]. It is possible that $\mathrm{B} 1 \mathrm{R}$ activation of NF-kB leads to anti-apoptotic properties, therefore inhibition of B1R demonstrated a significant increase in tumor apoptosis. Another possible explanation for the reduced tumor burden following B1R blockade could be due to a reduction in chronic inflammation normally seen in cancer as a result of increased expression and signalling of the B1R. In contrast $\mathrm{B} 2 \mathrm{R}$ is constitutively expressed and hence assumed to be mostly responsible for effecting normal physiological functions.

Our results show that blockade of either the B1R or the B2R resulted in significant reduction in tumor vascular density and this may be one of the mechanisms by which tumor progression is retarded. B1R and B2R activation have been implicated in angiogenesis and neovascularization in other studies. Kinins induce EC proliferation in cell cultures through the B1-cAMP pathway. B1R stimulation has been shown to induce neovascularization in the rabbit cornea [36], while B2R stimulation can activate the mitogen-activated protein kinase pathways (MAPK) and $\mathrm{P} 13 \mathrm{~K} / \mathrm{AKT}$, contributing to proliferation and angiogenesis [37-39]. Other studies have shown tumor suppression 

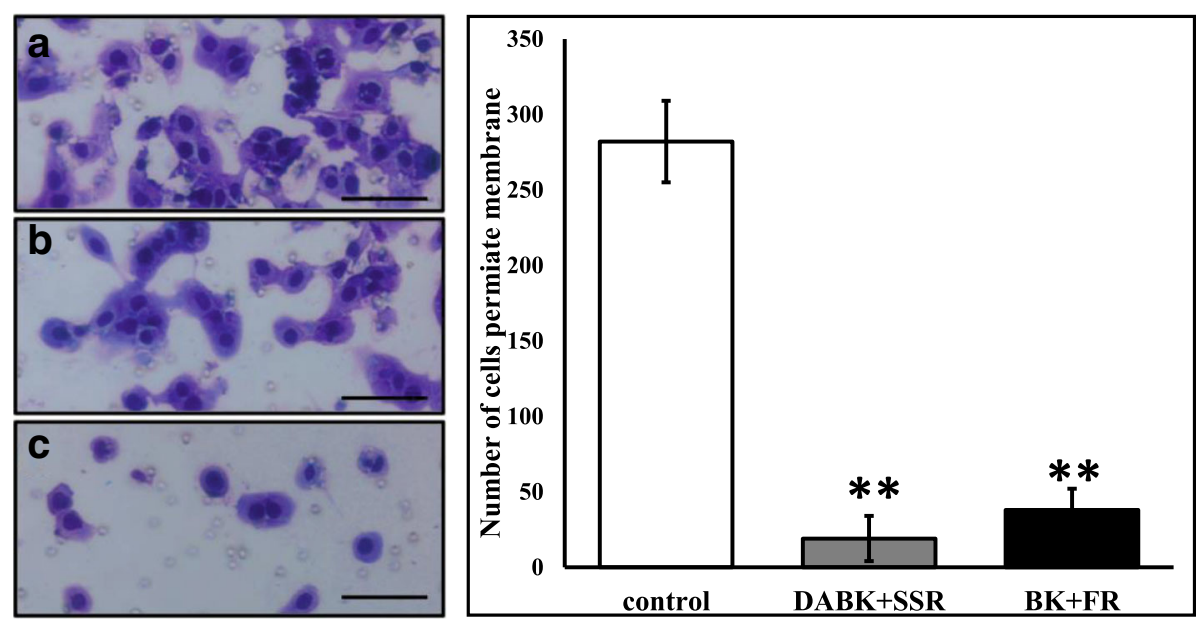

Fig. 6 The effect of kinin receptor antagonism on MoCR cell invasion. MoCR cells were seeded into upper chambers with kinin/ kinin-receptor inhibitor combinations in lower chambers. The membrane on the lowers surface of the upper chamber was coated with fibronectin and allowed to set. a Non-treated cells, b Cells treated with $10.0 \mu \mathrm{M}$ of SSR240612 (SSR) and $0.10 \mu \mathrm{M}$ DABK, c Cells treated with $10.0 \mu \mathrm{M}$ of FR173657 (FR) and $0.10 \mu \mathrm{M}$ BK, [E] Number of cells that permeated the membrane. Cells were culture for $21 \mathrm{~h}$ in $0.01 \%$ BSA RPMI media. The control was $0.01 \%$ BSA RPMI media. SSR240612 and FR173657 treatment significantly reduced the number of invasive MoCR cells. Results are presented as replicate mean \pm $\mathrm{SD}, 2$ replicates per group ( ${ }^{* *} \mathrm{p}<0.0001$ compared to control). 40X magnification; Bar $=25 \mu \mathrm{m}$

and angiogenic inhibition following treatment with B2R inhibition [40] or in kininogen knock out mice [12]. Moreover, Morbidelli et al. demonstrated the ability of BK to stimulate EC proliferation via activation of B1R or indirect activation of B2R, further supporting a role of kinin receptors in angiogenesis and tumor development [41].

In agreement with Wang et al. [22] we also detected B1R and B2R expression in both MoCR and SW480 colon cancer cells lines suggesting that receptor blockade may also have direct effects on the tumor cells. There are several studies which suggest that activation of $\mathrm{B} 1 \mathrm{R}$ and $\mathrm{B} 2 \mathrm{R}$ leads to stimulation of tumor cell proliferation and migration [37, 42, 43]. Unlike Barki-Harrington et al. who found increased proliferation following stimulation of $B 1 R$ and B2R [42], our in vitro study failed to show increased proliferation with B1R agonist (desArg9Bradykinin (DABK)), however, the involvement of B1R in proliferation cannot be completely ruled out, since treatment with a B1R antagonist (SSR240612) demonstrated significant reduction in tumor proliferation. McLean et al. found that the synthesis of DABK is significantly upregulated during inflammation [44]; it is possible that MoCR cells may have maximal DABK secretion therefore external addition of the DABK agonist does not further increase cell proliferation. Although DABK failed to increase tumor proliferation, our current study did find that BK treatment (B2R agonist) resulted in increased cell proliferation and the use of a B2R antagonist (FR173657) significantly decreased proliferation, further demonstrating that kinins do play a role in tumor proliferation. Further stimulation of kinin receptors was shown to increase tumor cell migration. Wang et al. reported that treatment with BK stimulated B2R and ERK1/2 leading to increased IL-6 production, ultimately increasing the invasiveness of colorectal cancer cells [22]., Ehrenfeld et al. found that activation of the B1R increased secretion of the metalloproteases (MMPs)-2 and -9 by breast cancer cells [11]. Previous studies have shown that MMP2 activates integrin $\alpha v \beta 3$ resulting in cellular invasion [45]; similarly MMP-9 has been shown to enhance metastatic capacity through activation of $\alpha v \beta 3$ in breast cancer cell lines [46] and $\alpha v \beta 6$ integrin activation has been shown to promote invasion of squamous cell carcinoma cells [45]. In agreement, using invasion assays, we observed significant decrease in tumor invasion following treatment with both B1R and B2R antagonists, further confirming a role of bradykinin receptors in CRLM migration.

\section{Conclusion}

Here we show that kinin receptors are involved in MoCR tumor progression In an in vivo CRLM mouse model tumor angiogenesis is inhibited and tumor progression retarded by $\mathrm{B} 1 \mathrm{R}$ and $\mathrm{B} 2 \mathrm{R}$ blockade. In addition, B1R inhibition led to significant reduction in the percentage of live tumor, possibly due to the increased tumor apoptosis. In an in vitro setting B1R and B2R antagonists decreased both tumor proliferation and migration. Taken together the results indicate that KKS manipulation could be a novel therapeutic target for treatment of colorectal cancer. 


\section{Additional files}

Additional file 1: Immunocytochemistry for detection of B1R and B2R on the colorectal cancer cell lines MOCR and SW480. [A] MoCR cells stained with naive rabbit lgG, [B] MoCR cells stained with rabbit anti-B1R, [C] SW480 cells stained with naive rabbit IgG, [D] SW480 cells stained with rabbit anti-B1R, [E] MoCR cells stained with naive rabbit, [F] MoCR cells stained with rabbit anti-B2R, [G] SW480 cells stained with naive rabbit IgG, and [H] SW480 cells stained with rabbit anti-B2R. Images taken at 20× magnification. Bar $=50 \mu \mathrm{m}$. (PDF $178 \mathrm{~kb}$ )

Additional file 2: The proliferative effect on MoCR cells exposed to kinins. MoCR cells were cultured for $48 \mathrm{~h}$ in RPMI media treated with [A] BK $(0.001,0.01,0.10$ and $1.0 \mu \mathrm{M})$ and [B] DABK $(0.001,0.01,0.10,1.0$ and $10.0 \mu \mathrm{M})$. The negative control was RMPI media contain no FBS; the positive control was RPMI media containing 5\% FBS. Results are presented as mean $\pm S D, 4$ replicates per group $\left({ }^{*} p<0.05\right.$ compared to negative control). (PDF $157 \mathrm{~kb}$ )

Additional file 3: Effects of BK on MoCR cell migration/invasion. A Boyden chamber assay was used. Transwell inserts $(8 \mu \mathrm{m}$ pore size membrane) were coated with fibronectin. Cells were loaded into the upper chamber and BK was added to the lower chamber containing serum-free media. The number of invading cells was counted after staining the membrane with eosin/thiazine. Exposure of 0.1 and $1 \mu \mathrm{M}$ BK increased MoCR cell migration in a dose dependent manner. Results are from three independent experiments in triplicate (average \pm SEM), ${ }^{*} p<0.05$. (PDF $204 \mathrm{~kb}$ )

\section{Abbreviations}

CRLM: colorectal liver metastasis; KKS: Kallikrein-Kinin System; MoCR: Mouse colorectal cancer

\section{Acknowledgements}

N/A

\section{Funding}

This study was supported by a grant from Cure Cancer Australia to Dr. Patricia Nunes da Costa. Cure Cancer Australia provided research support, they had no role in the study design, data collection, analysis and interpretation of results or in the preparation and submission of this manuscript

\section{Availability of data and materials}

The datasets generated and analysed during this study are presented in the Figures and Additional Files. Raw data are available from the corresponding author on reasonable request.

\section{Authors' contributions}

PdaC and CC conceived, designed and supervised the study. DW and LN performed the experiments. PdaC, DW, MP and TF analysed and interpreted the data. PdaC and LN wrote the manuscript. TF and MP edited the manuscript. All authors read and approved the final manuscript.

\section{Ethics approval}

All animal experiments were approved by the Austin Health Animal Ethics Committee in accordance with international guidelines for animal use. All efforts were made to minimize the number and suffering of animals

\section{Consent for publication}

N/A

\section{Competing interests}

The authors declare that they have no competing interests.

\section{Publisher's Note}

Springer Nature remains neutral with regard to jurisdictional claims in published maps and institutional affiliations.

\section{Author details}

'Department of Surgery, University of Melbourne, Austin Health, Lance Townsend Building Level 8, Studley Rd, Heidelberg, VIC 3084, Australia.
${ }^{2}$ Laboratório de Oncologia Experimental, Faculdade de Medicina da Universidade de São Paulo and Instituto do Câncer do Estado de São Paulo, São Paulo, Brazil.

Received: 3 August 2017 Accepted: 20 March 2018

Published online: 04 April 2018

\section{References}

1. Jemal A, Bray F, Center MM, Ferlay J, Ward E, Forman D. Global cancer statistics. CA Cancer J Clin. 2011;61(2):69-90.

2. Faivre J, Manfredi S, Bouvier AM. epidemiology of colorectal cancer liver metastases. Bull Acad Natl Med. 2003;187(5):815-22. discussion 822-813

3. Saenz NC, Cady B, McDermott WV Jr, Steele GD Jr. Experience with colorectal carcinoma metastatic to the liver. Surg Clin North Am. 1989; 69(2):361-70.

4. Chan LS, Daruwalla J, Christophi C. Selective targeting of the tumour vasculature. ANZ J Surg. 2008;78(11):955-67.

5. de Jong MC, Pulitano C, Ribero D, Strub J, Mentha G, Schulick RD, Choti MA, Aldrighetti L, Capussotti L, Pawlik TM. Rates and patterns of recurrence following curative intent surgery for colorectal liver metastasis: an international multi-institutional analysis of 1669 patients. Ann Surg. 2009; 250(3):440-8.

6. Neo JH, Malcontenti-Wilson C, Muralidharan V, Christophi C. Effect of ACE inhibitors and angiotensin II receptor antagonists in a mouse model of colorectal cancer liver metastases. J Gastroenterol Hepatol. 2007:22(4):577-84

7. da Costa PL, Sirois P, Tannock IF, Chammas R. The role of kinin receptors in cancer and therapeutic opportunities. Cancer Lett. 2014;345(1):27-38.

8. Su JB. Different cross-talk sites between the renin-angiotensin and the kallikrein-kinin systems. J Renin-Angiotensin-Aldosterone Syst. 2014;15(4): 319-28.

9. Figueroa CD, Ehrenfeld P, Bhoola KD. Kinin receptors as targets for cancer therapy. Expert Opin Ther Targets. 2012;16(3):299-312.

10. Fernandes PD, Gomes Nde M, Sirois P. The bradykinin B1 receptor antagonist R-954 inhibits Ehrlich tumor growth in rodents. Peptides. 2011; 32(9):1849-54

11. Ehrenfeld P, Conejeros I, Pavicic MF, Matus CE, Gonzalez CB, Quest AF, Bhoola KD, Poblete MT, Burgos RA, Figueroa CD. Activation of kinin B1 receptor increases the release of metalloproteases-2 and -9 from both estrogen-sensitive and -insensitive breast cancer cells. Cancer Lett. 2011; 301(1):106-18.

12. Ikeda Y, Hayashi I, Kamoshita E, Yamazaki A, Endo H, Ishihara K, Yamashina S, Tsutsumi Y, Matsubara H, Majima M. Host stromal bradykinin B2 receptor signaling facilitates tumor-associated angiogenesis and tumor growth. Cancer Res. 2004;64(15):5178-85.

13. Ishihara K, Kamata M, Hayashi I, Yamashina S, Majima M. Roles of bradykinin in vascular permeability and angiogenesis in solid tumor. Int Immunopharmacol. 2002;2(4):499-509.

14. Whalley ET, Figueroa CD, Gera L, Bhoola KD. Discovery and therapeutic potential of kinin receptor antagonists. Expert Opin Drug Discov. 2012;7(12): 1129-48.

15. Wu J, Akaike T, Hayashida K, Miyamoto Y, Nakagawa T, Miyakawa K, MullerEsterl W, Maeda $\mathrm{H}$. Identification of bradykinin receptors in clinical cancer specimens and murine tumor tissues. Int J Cancer. 2002;98(1):29-35.

16. Graness A, Adomeit A, Heinze R, Wetzker R, Liebmann C. A novel mitogenic signaling pathway of bradykinin in the human colon carcinoma cell line SW-480 involves sequential activation of a $\mathrm{Gq} / 11$ protein, phosphatidylinositol 3-kinase beta, and protein kinase Cepsilon. J Biol Chem 1998:273(48):32016-22

17. Zelawski W, Machnik G, Nowaczyk G, Plewka D, Lorenc Z, Sosada K, Stadnicki A. Expression and localisation of kinin receptors in colorectal polyps. Int Immunopharmacol. 2006;6(6):997-1002.

18. Kuruppu D, Christophi C, Bertram JF, O'Brien PE. Characterization of an animal model of hepatic metastasis. J Gastroenterol Hepatol. 1996; 11(1):26-32.

19. Malcontenti-Wilson C, Muralidharan V, Skinner S, Christophi C, Sherris D, O'Brien PE. Combretastatin A4 prodrug study of effect on the growth and the microvasculature of colorectal liver metastases in a murine model. Clin Cancer Res. 2001;7(4):1052-60.

20. Fifis T, Nguyen L, Malcontenti-Wilson C, Chan LS, Luiza Nunes Costa P, Daruwalla J, Nikfarjam M, Muralidharan V, Waltham M, Thompson EW, 
Chrisophi C. Treatment with the vascular disruptive agent OXi4503 induces an immediate and widespread epithelial to mesenchymal transition in the surviving tumor. Cancer medicine. 2013;2(5):595-610.

21. Ishizu K, Sunose N, Yamazaki K, Tsuruo T, Sadahiro S, Makuuchi H, Yamori T. Development and characterization of a model of liver metastasis using human colon cancer HCT-116 cells. Biol Pharm Bull. 2007:30(9):1779-83.

22. Wang $G, Y e$ Y, Zhang $X$, Song J. Bradykinin stimulates IL-6 production and cell invasion in colorectal cancer cells. Oncol Rep. 2014;32(4):1709-14.

23. Czokalo M, Palka M, Kralisz P, Filipkowski T. Kallikrein-kinin system in patients with neoplastic diseases. Rocz Akad Med Bialymst. 1996;41(2):417-28.

24. Maeda H, Akaike T, Wu J, Noguchi Y, Sakata Y. Bradykinin and nitric oxide in infectious disease and cancer. Immunopharmacology. 1996;33(1-3):222-30.

25. Dlamini Z, Bhoola KD. Upregulation of tissue kallikrein, kinin B1 receptor and kinin B2 receptor in mast and giant cells infiltrating oesophageal squamous cell carcinoma. J Clin Pathol. 2005;58(9):915-22.

26. Greco S, Muscella A, Elia MG, Romano S, Storelli C, Marsigliante S. Mitogenic signalling by B2 bradykinin receptor in epithelial breast cells. J Cell Physiol. 2004;201(1):84-96.

27. Rittenhouse HG, Finlay JA, Mikolajczyk SD, Partin AW. Human Kallikrein 2 (hK2) and prostate-specific antigen (PSA): two closely related, but distinct, kallikreins in the prostate. Crit Rev Clin Lab Sci. 1998;35(4):275-368.

28. Yousef GM, Diamandis EP. The new human tissue kallikrein gene family: structure, function, and association to disease. Endocr Rev. 2001;22(2): 184-204.

29. Kashuba E, Bailey J, Allsup D, Cawkwell L. The kinin-kallikrein system: physiological roles, pathophysiology and its relationship to cancer biomarkers. Biomarkers. 2013;18(4):279-96.

30. Costa-Neto CM, Dillenburg-Pilla P, Heinrich TA, Parreiras-e-Silva LT, Pereira MG, Reis RI, Souza PP. Participation of kallikrein-kinin system in different pathologies. Int Immunopharmacol. 2008;8(2):135-42.

31. Bhoola K, Ramsaroop R, Plendl J, Cassim B, Dlamini Z, Naicker S. Kallikrein and kinin receptor expression in inflammation and cancer. Biol Chem. 2001; 382(1):77-89.

32. Medeiros R, Cabrini DA, Ferreira J, Fernandes ES, Mori MA, Pesquero JB, Bader M, Avellar MC, Campos MM, Calixto JB. Bradykinin B1 receptor expression induced by tissue damage in the rat portal vein: a critical role for mitogen-activated protein kinase and nuclear factor-kappaB signaling pathways. Circ Res. 2004;94(10):1375-82

33. Chen BC, Yu CC, Lei HC, Chang MS, Hsu MJ, Huang CL, Chen MC, Sheu JR, Chen TF, Chen TL, et al. Bradykinin B2 receptor mediates NF-kappaB activation and cyclooxygenase-2 expression via the Ras/Raf-1/ERK pathway in human airway epithelial cells. J Immunol. 2004;173(8):5219-28.

34. Webster GA, Perkins ND. Transcriptional cross talk between NF-kappaB and p53. Mol Cell Biol. 1999;19(5):3485-95.

35. Moreau ME, Garbacki N, Molinaro G, Brown NJ, Marceau F, Adam A. The kallikrein-kinin system: current and future pharmacological targets. J Pharmacol Sci. 2005;99(1):6-38

36. Parenti A, Morbidelli L, Ledda F, Granger HJ, Ziche M. The bradykinin/ B1 receptor promotes angiogenesis by up-regulation of endogenous FGF-2 in endothelium via the nitric oxide synthase pathway. FASEB J. 2001;15(8):1487-9.

37. Lu DY, Leung YM, Huang SM, Wong KL. Bradykinin-induced cell migration and COX-2 production mediated by the bradykinin B1 receptor in glioma cells. J Cell Biochem. 2010;110(1):141-50.

38. Greco S, Elia MG, Muscella A, Romano S, Storelli C, Marsigliante S. Bradykinin stimulates cell proliferation through an extracellular-regulated kinase 1 and 2-dependent mechanism in breast cancer cells in primary culture. J Endocrinol. 2005;186(2):291-301.

39. Leeb-Lundberg LM, Marceau F, Muller-Esterl W, Pettibone DJ, Zuraw BL. International union of pharmacology. XLV. Classification of the kinin receptor family: from molecular mechanisms to pathophysiological consequences. Pharmacol Rev. 2005:57(1):27-77.

40. Ishihara K, Hayash I, Yamashina S, Majima M. A potential role of bradykinin in angiogenesis and growth of S-180 mouse tumors. Jpn J Pharmacol. 2001; 87(4):318-26.

41. Morbidelli L, Parenti A, Giovannelli L, Granger HJ, Ledda F, Ziche M. B receptor involvement in the effect of bradykinin on venular endothelial cell proliferation and potentiation of FGF-2 effects. Br J Pharmacol. 1998;124(6):1286-92

42. Barki-Harrington L, Bookout AL, Wang G, Lamb ME, Leeb-Lundberg LM, Daaka Y. Requirement for direct cross-talk between B1 and B2 kinin receptors for the proliferation of androgen-insensitive prostate cancer PC3 cells. Biochem J. 2003;371(Pt 2):581-7.

43. Naidoo S, Raidoo DM. Tissue kallikrein and kinin receptor expression in an angiogenic co-culture neuroblastoma model. Metab Brain Dis. 2006; 21(2-3):253-65

44. McLean PG, Perretti $M$, Ahluwalia A. Kinin B(1) receptors and the cardiovascular system: regulation of expression and function. Cardiovasc Res. 2000;48(2):194-210.

45. Brooks PC, Stromblad S, Sanders LC, von Schalscha TL, Aimes RT, StetlerStevenson WG, Quigley JP, Cheresh DA. Localization of matrix metalloproteinase MMP-2 to the surface of invasive cells by interaction with integrin alpha $\vee$ beta 3. Cell. 1996;85(5):683-93.

46. Rolli M, Fransvea E, Pilch J, Saven A, Felding-Habermann B. Activated integrin alphavbeta3 cooperates with metalloproteinase MMP-9 in regulating migration of metastatic breast cancer cells. Proc Natl Acad Sci U S A. 2003:100(16):9482-7.

\section{Submit your next manuscript to BioMed Central and we will help you at every step:}

- We accept pre-submission inquiries

- Our selector tool helps you to find the most relevant journal

- We provide round the clock customer support

- Convenient online submission

- Thorough peer review

- Inclusion in PubMed and all major indexing services

- Maximum visibility for your research

Submit your manuscript at www.biomedcentral.com/submit
) Biomed Central 